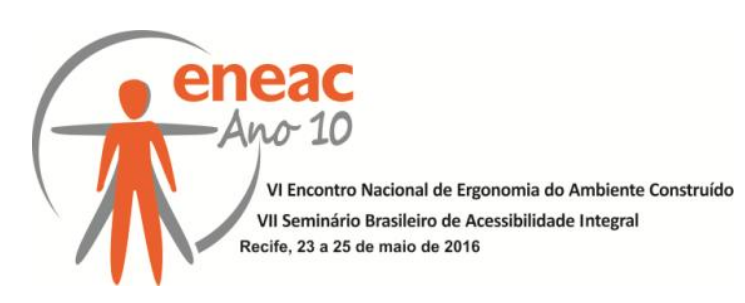

\title{
PROPOSTA DE CONDICIONAMENTO ACÚSTICO UTILIZANDO MATERIAIS SUSTENTÁVEIS DO AUDITÓRIO DAS FACULDADES INTEGRADAS DE PATOS-PB
}

\author{
BARBOSA, Déborah Mais Fragoso (1); MACHADO, Andressa Medeiros \\ (2); BARBOSA, Luiz Henrique Frazão (3); \\ GOMES, Emmily Gersica Santos (4) \\ (1) Faculdades Integradas de Patos, Graduando Arquitetura e Urbanismo \\ e-mail:deborahmais@outlook.com \\ (2) Faculdades Integradas de Patos, Graduando Arquitetura e Urbanismo \\ e-mail:andressa.medeiros2009@hotmail.com \\ (3) Faculdades Integradas de Patos, Graduando Arquitetura e Urbanismo \\ e-mail:henrique frazão93@hotmail.com
}

(4) Faculdades Integradas de Patos, Mestra em Arquitetura e Urbanismo- UFPB/PPGAU

e-mail:emmilygersica@hotmail.com

\begin{abstract}
RESUMO
Este artigo apresenta um estudo acústico realizado no auditório de uso múltiplo, localizado nas Faculdades Integradas de Patos. No ambiente foram avaliados dois parâmetros acústicos, o tempo de reverberação e a geometria do espaço, objetivando compreender o comportamento da reflexão do som em seu interior. Utilizou-se o levantamento do coeficiente de absorção sonora, de cada material das superfícies aparentes do auditório, para efeito dos cálculos de tempo de reverberação. Por fim, desenvolveu-se uma proposta sustentável para melhoria da qualidade sonora do local.
\end{abstract}

Palavras chave: auditório; acústica; coeficiente de absorção sonora e tempo de reverberação.

\begin{abstract}
This paper presents an acoustic study in an auditorium of multiple use, located in the Faculdades Integradas de Patos. In the environment have been assessed two acoustic parameters, the reverberation time and the geometry of space, aiming to understand of the sound reflection behavior inside. We used the survey of the sound absorption coefficient, of each material of the apparent surfaces of the auditorium, for the purposes of reverberation time calculations.
\end{abstract}

Keywords: auditorium; acoustic; sound absorption coefficiente and reverberation time. 


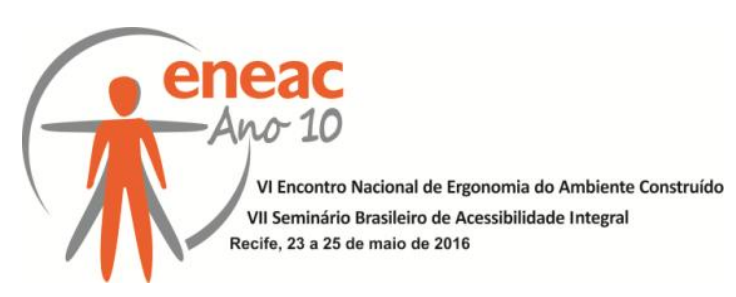

\section{INTRODUÇÃO}

Desde a antiguidade, o desempenho acústico tem sido uma preocupação ao se projetar teatros, cinemas e auditórios, pois nessas construções, a exigência de conforto acústico é essencial para se garantir uma boa sonoridade e percepção de todas as frequências sonoras emitidas. A acústica implica diretamente na forma como as ondas sonoras se propagam em um ambiente, por isso, os espaços necessitam de tratamento acústico para que o som dentro dos ambientes atinja uma qualidade satisfatória, proporcionando uma boa inteligibilidade do som e consequentemente conforto aos seus usuários.

Segundo De Marco (1982), dentro das diversas funções da acústica, a arquitetônica delimita-se em duas áreas específicas: Defesa contra o ruído: onde os sons indesejáveis devem ser eliminados, ou então amortecidos, isto se refere tanto a intromissão de ruídos alheios ao local, através dos diferentes fechamentos, quanto àquelas produzidos no próprio interior; Controle de sons no recinto: nos locais onde é importante uma comunicação sonora (salas de aula, teatros, auditórios), necessita-se de uma distribuição homogênea do som que preserve a qualidade e a inteligibilidade da comunicação, evitando defeitos acústicos comuns (ecos, ressonâncias, reverberação excessiva).

Para se resolver esses, e outros problemas, é necessário entender os princípios básicos desses fenômenos acústicos. É importante considerar as formas de emissão do som, sua propagação nos meios materiais e seu comportamento diante de barreiras levando em conta as propriedades acústicas dos materiais existentes nos ambientes, sua forma, tamanho e disposição.

Neste trabalho será realizado o estudo do controle de sons do recinto através da verificação dos coeficientes de absorção dos materiais, cálculo de reverberação e estudo da geometria local, não será proposto alteração na defesa contra o ruído, por fazer parte de uma proposta de isolamento acústico que não é o foco desta pesquisa.

Essa pesquisa se justifica na verificação do auditório de múltiplas funções do bloco de Odontologia das Faculdades Integradas de Patos, se o mesmo atende às funções determinadas por De Marco (1982) de defesa contra o ruído e controle de som no recinto. Segundo ele, "o projeto de auditórios é um dos mais complexos dentro da acústica arquitetônica" (DE MARCO,1982).

O objetivo geral desse artigo é elaborar uma proposta para melhoria da qualidade acústica do auditório de odontologia das Faculdades Integradas de Patos - PB, visando à utilização de materiais sustentáveis. Como forma de atingir este objetivo foi realizado um diagnóstico da acústica do auditório, verificando os coeficientes de absorção e identificando se os mesmos estavam dentro dos padrões da acústica para se atingir um tempo ótimo de reverberação (Tor). O que possibilitou realizar uma proposta para a melhoria da acústica no auditório. Além disso, proporcionar uma alerta aos profissionais de Arquitetura e Engenharia sobre a importância dessa variável de projeto acústico, assim como, auxiliar no desenvolvimento de um ambiente mais ajustado aos problemas referentes à propagação das ondas sonoras.

\section{ACÚSTICA ARQUITETÔNICA}

A Acústica é o ramo da física que estudo e analisa as ondas sonoras, a sua propagação em meios tanto fluídos quanto sólidos e as suas relações com o ser humano, são necessários três elementos fundamentais: uma fonte sonora, um receptor e um meio de propagação.

Segundo De Marco (1982), a onda se desloca com uma velocidade que depende das características do meio, da pressão, da umidade e da temperatura, com isso, a frequência e 


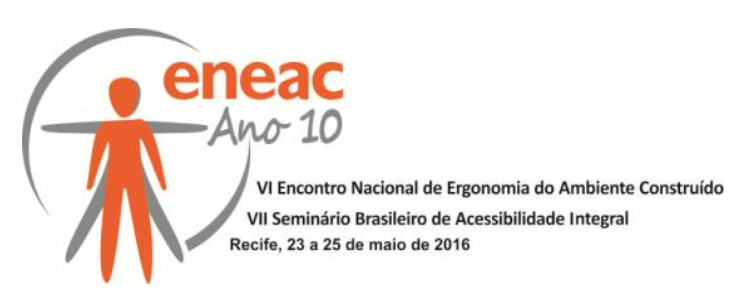

amplitude de oscilação não interferem na mesma. Para chegar até o ser humano, elas atingem uma membrana chamada tímpano que passa a vibrar com a mesma frequência das ondas, transmitindo ao cérebro, por impulsos elétricos, a sensação do som.

A frequência sonora, de acordo com Silva (2005), é determinada pelo número de oscilações completas por segundo, ou seja, o número de idas e voltas completas de particulares vibrantes. A frequência é medida em ciclos por segundos (C.P.S) ou em Hertz $(\mathrm{Hz})$ e caracterizada como grave quando a altura do som possui valores baixos e quando elevados denomina-se de alto ou agudo. Apenas as vibrações dentro de certos limites de frequência é que são audíveis pelo homem, que possuem um limite compreendido pelo órgão auditivo entre 16 a $30000 \mathrm{~Hz}$.

Cada material possui um coeficiente de absorção sonora, que na maioria das vezes é diferente para cada frequência. Esta variável influencia diretamente no tempo de reverberação local, e juntamente com o volume e a geometria local definem como o som se comporta no ambiente.

Souza (2006) afirma que a boa acústica é obtida pelas formas irregulares e difusoras de superfície e, principalmente pela aplicação balanceada de materiais de construção, de forma que sua utilização e distribuição influenciam na reverberação do ambiente, ou seja, o tempo de reverberação é inversamente proporcional à qualidade de materiais fonoabsorventes. Portanto, a escolha dos materiais é de extrema importância para um projeto acústico.

Existem dois tipos de materiais, os fonorrefletores: que apresentam valores de absorção próximos a zero e são impermeáveis, com pouca porosidade (pedras, madeiras, vidros) e os fonoabsorventes com coeficiente de absorção próximo a 1,00 e com característica predominante a absorção sonora, divididos em porosos, painéis e ressoadores. Porém, ao contrário dos demais autores, De Marco (1982) diz que todo material é fonoabsorvente, porém, alguns têm característica excelente de absorção sonora e outros, de péssima absorção sonora.

Maia e Salgado (2005), assim como a NBR 10152 (ABNT 1987), afirmam que para atingir um desempenho acústico de qualidade dentro das edificações deve existir um controle entre os ruídos internos e externos em níveis adequados, do tempo de reverberação e da geometria local. Contudo, esta pesquisa não analisará o isolamento acústico local, por efeito de viabilidade de execução futura, foi estudado unicamente o tempo de reverberação e a geometria local do auditório em conjunto com os parâmetros estabelecidos por norma.

Para impedir que os ruídos dessas fontes prejudiquem as atividades realizadas em um auditório, deve-se levar em consideração a capacidade que os elementos presentes no local possuem de isolar o som e refletir de acordo com a necessidade local. O coeficiente de absorção de materiais expostos em ambiente consiste na quantidade de energia absorvida e refletida pelos materiais, valores esses que variam de acordo com suas características físicas de porosidade, rigidez e sua forma de instalação e os mesmos se alteram com as frequências sonoras, e esses valores variam entre 0,00 a 1,00 .

Em relação à geometria local de auditórios, Souza (2006), afirma que a forma retangular do auditório gera melhorias na acústica do ambiente, porém junto a essa forma, vem o problema do paralelismo das paredes, que causa grande reflexão sonora, gerando assim grandes defeitos acústicos.

O tempo de reverberação relaciona o volume do ambiente e consiste em o tempo em segundos que o som demora a extinguir-se, ou seja, o período de permanência do som no ar, sendo necessário que o nível de pressão sonora decaia em $60 \mathrm{~dB}$ depois que a fonte sonora interrompa a emissão. Segundo De Marco (1982) o tempo de reverberação ideal para auditórios é de $0,72 \mathrm{~s}$. Com essas informações e com auxílio da fórmula de Sabine é possível determinar o tempo de reverberação. O volume do ambiente, a superfície dos 


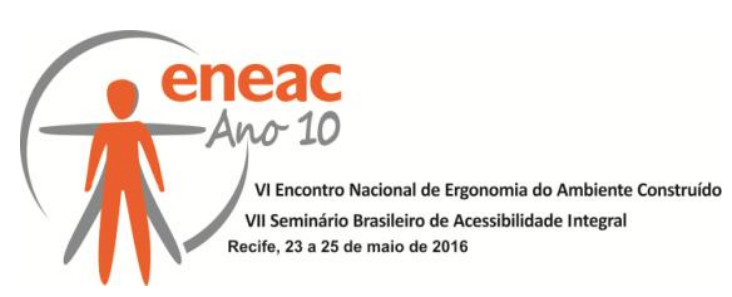

materiais e seus devidos coeficientes de absorção definem o valor do tempo de reverberação para cada frequência em estudo (Equação 01).

$$
\mathrm{T}=0,161 . \mathrm{V} / \mathrm{A}
$$

Onde:

T: Tempo de Reverberação;

$\mathrm{V}$ : Volume em $\mathrm{m}^{3}$;

A: Absorção em m²;

0,161 : constante que torna o cálculo mais preciso.

\section{OBJETO DE ESTUDO}

O auditório está localizado no bloco de Odontologia das Faculdades Integradas de Patos, localizada no bairro Belo Horizonte, na cidade de Patos, sertão da Paraíba. Possui $98,17 \mathrm{~m}^{2}$ e volume de $204,336 \mathrm{~m}^{3}$ (Figura 1). O acesso ao auditório dar-se a partir de um corredor, que também o conecta a salas de aula e a banheiros.

Todos os cursos da faculdade fazem uso do local, que é utilizado para diversas atividades, como congressos, palestras, simpósios e apresentações. O fluxo de pessoas no ambiente é constante e diário.

O recinto encontra-se com diversos equipamentos e mobiliários, dentre eles: 132 cadeiras estofadas com couro sintético, sendo 127 (cento e vinte e sete) na plateia e 05 (cinco) localizadas no palco; 06 (seis) janelas redondas com diâmetro de $1 \mathrm{~m}$, todas de vidro e revestidas com películas de plástico; 01 (um) porta principal de MDF medindo $2,10 \mathrm{~m} \times$ 0,80m; 01 (um) palco de MDF com altura de 0,30 m; uma mesa em MDF com dimensões de $4,20 \mathrm{~m} \times 0,65 \mathrm{~m} \times 0,75 \mathrm{~m} ; 12$ luminárias distribuídas por todo o auditório, com duas lâmpadas fluorescentes, cada luminária, totalizando 24 (vinte e quatro) unidades; duas centrais de ar condicionado; 01 (um) computador; 01 (um) data show; 08 (oito) caixas de som e 01 (um) púlpito.

Figura 1 - (a) Localização do auditório de Odontologia dentro da Faculdade Integrada de Patos; (b) Planta baixa do auditório de Odontologia
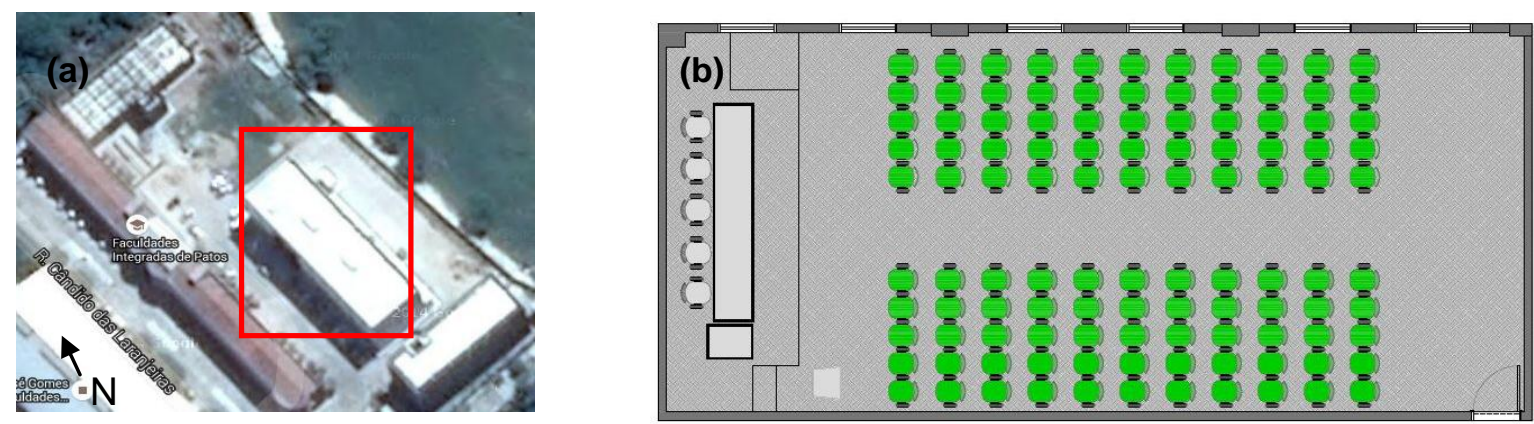

Fonte: (GOOGLE EARTH, 2016; AUTORES, 2016). 


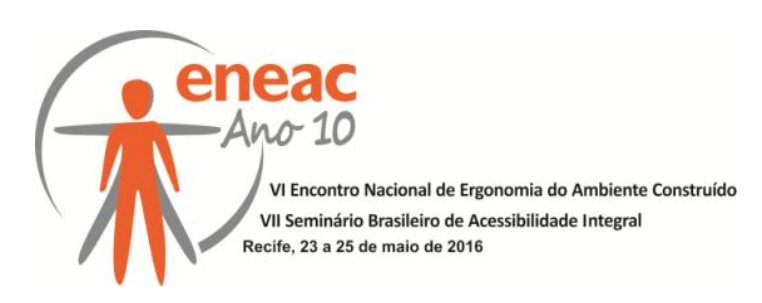

\section{METODOLOGIA}

\subsection{Levantamento físico}

Através da visita in loco foi realizado a medição do ambiente e a contabilização dos equipamentos existentes no auditório. Foram identificados os materiais que compõe suas superfícies do teto, parede e piso. Não foi constatado nenhum material que favorecesse o isolamento acústico, mas as especificações desempenharam grande importância para o diagnóstico da reverberação.

Além disso, foi analisado o fluxo de pessoas que utilizam o local e a frequência que esses frequentavam 0 ambiente, e quais atividades desenvolviam. Ressalta-se a grande importância em entender esse processo, pois, para a realização do cálculo de reverberação a quantidade de pessoas e o volume do ambiente são imprescindíveis.

Posteriormente a contabilização dos equipamentos do auditório foi realizada uma pesquisa bibliográfica para a especificação dos coeficientes de absorção sonora, das frequências representativas da fala humana, como o proposto por De Marco (1982). Estes coeficientes se dão em valores diferentes para cada frequência e nesse estudo adotou-se, como já citado, estudar três frequências: grave $(125 \mathrm{~Hz})$, aguda $(2000 \mathrm{~Hz})$ e média $(500 \mathrm{~Hz})$. Esta variável que em conjunto com outros dados, como o volume, número de ocupantes e áreas das superfícies fornecerá o tempo de reverberação do auditório. Com base nestas informações foi possível iniciar o processo de análise e correção do tempo de reverberação.

\subsection{Análise de desempenho acústico: tempo de reverberação e geometria do local}

Para obtenção do tempo de reverberação, do auditório, foram realizados cálculos utilizando a fórmula de Sabine como indicado por De Marco, 1982. Para a análise dos parâmetros acústicos e a proposta de condicionamento tomou-se como base a NBR 12179: "Tratamento acústico em recintos fechados" (ABNT, 2002).

Com os coeficientes de absorção dos materiais expostos no ambiente (cadeira estofada com couro sintético; porta de madeira; tapete de borracha; tábuas de madeira; reboco liso e gesso) e auxílio do software Excel, da Microsoft, deu-se início aos cálculos de tempo de reverberação para as frequências de $500 \mathrm{~Hz}, 125 \mathrm{~Hz}$ e $2000 \mathrm{~Hz}$ (Tabela 1). Quanto às áreas das superfícies do auditório, estas foram atingidas através do AutoCAD 2015, programa desenvolvido pela Autodesk.

Após a realização dos cálculos foi possível realizar a comparação da situação atual do auditório com o prescrito em norma. $O$ valor adotado como tempo ótimo de reverberação para o auditório (Tor) foi de 0,72s, como sugere De Marco (1982). Para efeito de melhor esclarecimento do valor do tempo encontrado para o tempo de reverberação, realizou-se um estudo das reflexões sonoras e da geometria do auditório.

\subsection{Proposta condicionamento acústico}

Além do diagnóstico da situação atual fez-se necessário uma proposta de melhoria no tempo de reverberação. As especificações de materiais que minimizam os problemas, causados na concepção arquitetônica do ambiente em estudo, também foi realizada após o 


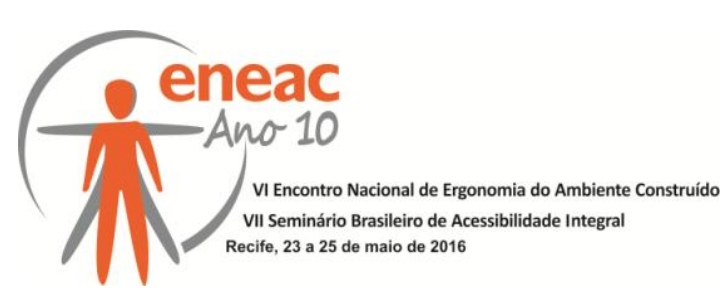

desenvolvimento da memória de cálculo (equação de Sabine), fundamentado no tempo ótimo de reverberação e valor ideal de absorção a ser atingida.

Segundo De Marco (1982), em relação ao comportamento do som no ambiente, o tempo de reverberação é o mais importante, pois, se a reverberação persiste muito tempo depois do som, o tempo de reverberação do ambiente fica alto, prejudicando a inteligibilidade. Visando este princípio e o de manter o baixo custo e a sustentabilidade, optou-se por não modificar a maior parte dos equipamentos existentes. Com isso, várias tentativas foram realizadas até chegar ao Tempo de reverberação final do auditório. A proposta tridimensional foi executada com auxílio do Scketchup, para modelagem, e do Lumion 3D, para renderização.

\section{RESULTADOS}

O presente tópico trata da descrição dos dados e discussão dos resultados obtidos a partir da análise do comportamento acústico do auditório estudado. A tabela 1 descreve os materiais que compõe o interior do auditório e demonstra os valores encontrados dos coeficientes de absorção sonora, para as frequências de $125 \mathrm{~Hz}, 500 \mathrm{~Hz}$ e $2000 \mathrm{~Hz}$.

Tabela 1 - Materiais existentes

\begin{tabular}{|c|c|c|c|}
\hline \multirow{2}{*}{$\begin{array}{c}\text { MATERIAIS } \\
\text { ALTERADOS }\end{array}$} & $\mathbf{5 0 0 ~ H z}$ & $\mathbf{1 2 5 ~ H z}$ & $\mathbf{2 0 0 0 ~ H z}$ \\
\cline { 2 - 4 } & 0,15 & 0,13 & 0,07 \\
\hline $\begin{array}{c}\text { Cadeira estofada } \\
\text { com couro sintético }\end{array}$ & 0,03 & - & - \\
\hline $\begin{array}{c}\text { Vidraça na Janela } \\
\text { Porta de madeira } \\
\text { fechada }\end{array}$ & 0,06 & 0,14 & 0,10 \\
\hline $\begin{array}{c}\text { Tapete de borracha } \\
\text { Tábua de madeira } \\
\text { 2,1 cm }\end{array}$ & 0,08 & 0,04 & 0,03 \\
\hline $\begin{array}{c}\text { Parede de alvenaria } \\
\text { pintada }\end{array}$ & 0,10 & 0,10 & 0,08 \\
\hline $\begin{array}{c}\text { Cerâmica (piso) } \\
\text { Gesso }\end{array}$ & 0,02 & 0,01 & 0,02 \\
\hline
\end{tabular}

Fonte: Adaptado de NBR 12179 (ABNT, 1992).

O cálculo do tempo de reverberação da situação atual do auditório na situação atual foi realizado levando-se em considerando os materiais descritos na tabela acima, um volume de $204,336 \mathrm{~m}^{3}$, e o tempo ótimo de reverberação de 0,72s (Tabela 02). 


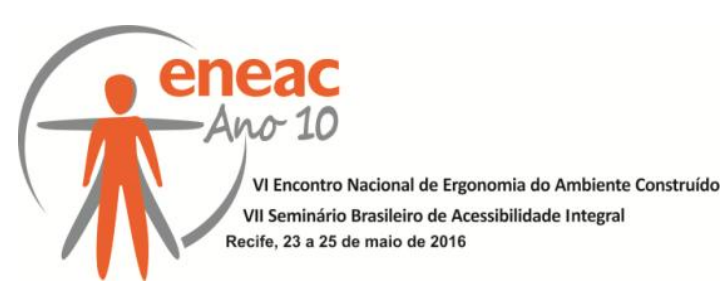

Tabela 2 - Resultados dos cálculos de tempo de reverberação atual do auditório

\begin{tabular}{|c|c|c|c|c|c|c|c|c|c|c|}
\hline \multicolumn{11}{|c|}{ Planilha Tempo de Reverberação atual } \\
\hline \multirow{3}{*}{ Amb.: } & \multirow{3}{*}{$\begin{array}{l}\text { Auditório do Bloco de } \\
\text { Odontologia das FIP }\end{array}$} & Larg. & Comp. & Alt. & \multicolumn{2}{|c|}{ Volume } & Ocup. & \multicolumn{2}{|c|}{ V/Ocup. } & Tor \\
\hline & & 6,6 & 12,9 & 2,4 & \multicolumn{2}{|c|}{204,336} & 132 & \multicolumn{2}{|c|}{1,55} & 0,72 \\
\hline & & \multicolumn{9}{|c|}{ FREQÜENCIA } \\
\hline \multirow{2}{*}{\multicolumn{2}{|c|}{ Especificação }} & \multirow[b]{2}{*}{ Si } & \multicolumn{2}{|c|}{$500 \mathrm{~Hz}$} & \multicolumn{3}{|c|}{$125 \mathrm{~Hz}$} & \multicolumn{3}{|c|}{$2000 \mathrm{~Hz}$} \\
\hline & & & \multirow{2}{*}{$\frac{\alpha \mathbf{i}}{0,150}$} & Si $x \alpha \mathbf{i}$ & $\alpha \mathbf{i}$ & \multicolumn{2}{|c|}{ Si $x \alpha i$} & $\alpha \mathbf{i}$ & \multicolumn{2}{|c|}{ Si $x \alpha \mathbf{i}$} \\
\hline 1 & $\begin{array}{l}\text { Cadeira estofada com } \\
\text { couro sintético }\end{array}$ & 95,04 & & 14,256 & 0,130 & \multicolumn{2}{|c|}{12,355} & 0,070 & \multicolumn{2}{|c|}{6,653} \\
\hline 2 & Vidraça na janela & 4,68 & 0,030 & 0,140 & - & \multicolumn{2}{|c|}{0,000} & - & \multicolumn{2}{|c|}{0,000} \\
\hline 3 & $\begin{array}{l}\text { Porta de madeira } \\
\text { fechada }\end{array}$ & 1,68 & 0,060 & 0,101 & 0,140 & \multicolumn{2}{|c|}{0,235} & 0,100 & \multicolumn{2}{|c|}{0,168} \\
\hline 4 & Tapete de borracha & 1,24 & 0,080 & 0,099 & 0,040 & \multicolumn{2}{|c|}{0,050} & 0,030 & & 037 \\
\hline 5 & Tábua de madeira & 34,89 & 0,100 & 3,489 & 0,100 & 3,4 & 489 & 0,080 & & 791 \\
\hline 6 & $\begin{array}{l}\text { Parede de alvenaria } \\
\text { pintada }\end{array}$ & 94,22 & 0,020 & 1,884 & 0,010 & 0,9 & 942 & 0,020 & & 884 \\
\hline 7 & Cerâmica (Piso) & 86,36 & 0,010 & 0,864 & 0,010 & 0,8 & 864 & 0,020 & & 727 \\
\hline 8 & Gesso & 98,18 & 0,030 & 2,945 & 0,040 & 3,9 & 927 & 0,020 & & 964 \\
\hline & $\begin{array}{l}\text { Tempo ótimo de } \\
\text { reverberação (s) }\end{array}$ & & 0,72 & & & 06 & & & 72 & \\
\hline Absc & orção total calculada & & 23,78 & & & 86 & & & ,22 & \\
\hline & Absorção ideal & & 45,69 & & & 08 & & & 69 & \\
\hline & $\begin{array}{l}\text { npo de reverberação } \\
\text { calculado (tr) }\end{array}$ & & 1,38 & & & 50 & & & 16 & \\
\hline
\end{tabular}

Fonte: (AUTORES, 2016)

A princípio a situação atual do auditório apresentou valores contraditórios em relação ao tempo de reverberação, este, se encontrou acima do ideal. A absorção total do ambiente demonstrou valores bem abaixo do indicado, o que revela a consequência da baixa utilização de materiais fonoabsorvente. A absorção ideal seria de 45,69 para a frequência média $(500 \mathrm{~Hz})$, de 31,08 para a grave $(125 \mathrm{~Hz})$ e 45,69 para a aguda $(2000 \mathrm{~Hz})$, porém a 


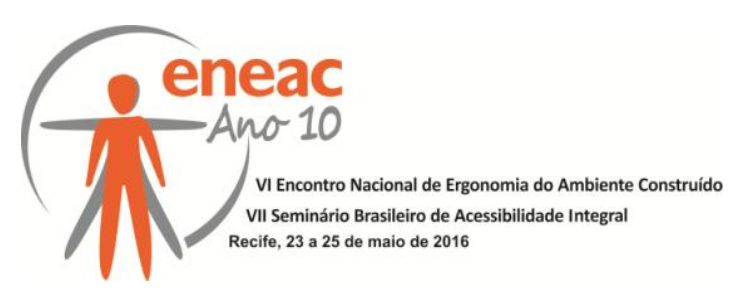

situação atual do auditório apontou valores de 23,78, 21,86 e 15,22 respectivamente para as frequências de $500 \mathrm{~Hz}, 125 \mathrm{~Hz}$ e $2000 \mathrm{~Hz}$ (Tabela 2).

De Marco (1982) aponta que o tempo ótimo de reverberação para a frequência de $500 \mathrm{~Hz}$ é $0,72 \mathrm{~s}$; porém o tempo de reverberação atingido pela sala foi o de $1,38 \mathrm{~s}$. Para a frequência de $125 \mathrm{~Hz}$ o ideal seria de 1,06s, mas o valor encontrado foi o de 1,50s. A frequência mais aguda $(2000 \mathrm{~Hz})$ demonstrou o mais elevado tempo de reverberação encontrado, chegando a atingir $2,16 \mathrm{~s}$.

O principal problema encontrado no auditório de Odontologia das Faculdades Integradas de Patos foi sua geometrização e apesar da forma não entrar nos cálculos de tr, ela é de fundamental importância para o estudo da reflexão sonora, conforma mostra a figura abaixo (Figura 2)

\section{Figura 2 - Estudo da geometria local}

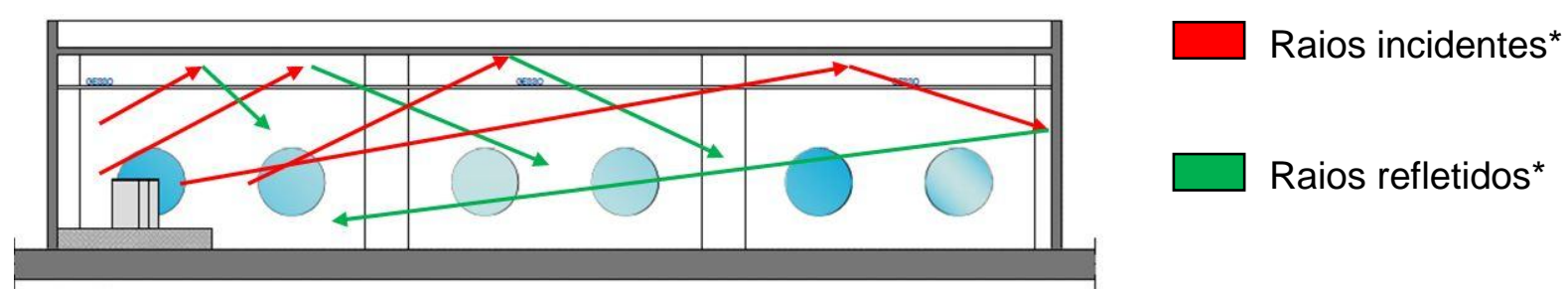

*Na imagem os raios sonoros são refletidos com ângulos iguais aos raios de incidência

Fonte: (AUTORES 2016)

Através de um corte esquemático, simulando uma fonte sonora acima do palco é possível observar o comportamento dos raios sonoros. "Considerando que raios sonoros, que refletem nas diversas superfícies internas de um ambiente analisado" (SIMÕES et al 2011) e também, que a direção das reflexões é determinada pela geometria do local, pode-se afirmar que o auditório apesar de ter uma geometria retangular, que favorece a acústica local, não apresenta nenhuma falta de paralelismo entre as paredes, o que também melhora a acústica local. Estes fatores em conjunto com a escassez de materiais com alto coeficiente de absorção sonora contribuíram para o baixo desempenho do auditório.

Para Simões et al (2011) A reflexão quando explorada arquitetônicamente, por meio de formas e direcionamento apropriados de espelhos acústicos, é um excelente instrumento para permitir o reforço e a distribuição sonora, aumentando a intensidade e homogeneidade do som ambiente. Em auditórios, esse recurso deve ser muito utilizado, pois como o som direto tende a perder sua intensidade, principalmente para os lugares mais afastados da fonte, os espelhos acústicos colaboram na intensidade do nível sonoro, outro ponto que deve ser observado no projeto.

Para amenizar a situação do local foi proposta a utilização de dois novos materiais. Em todas as parede que contém janelas, assim como no palco, foi especificado o uso de paredes grossas; e carpete de juta em todo o piso do auditório. A efeito dos cálculos usouse coeficientes de absorção com os valores indicados por norma (ABNT, 1992) de 0,4 para a frequência de $500 \mathrm{~Hz} ; 0.25$ para a frequência de $125 \mathrm{~Hz}$ e 0,60 para $2000 \mathrm{~Hz}$.

Após a realização dos cálculos com as alterações indicadas, pôde-se observar que houve algumas alterações que proporcionaram melhoria no tempo de reverberação e na absorção do local. Na frequência de $500 \mathrm{~Hz}$, o tempo de reverberação calculado foi de $0,78 \mathrm{~s}$, e a sua absorção foi de 42,39. Para a frequência de $125 \mathrm{~Hz}$, o novo tempo de reverberação encontrado foi de $1,02 \mathrm{~s}$, e sua absorção sonora de 32,23 . A frequência de $2000 \mathrm{~Hz}$, foi a 


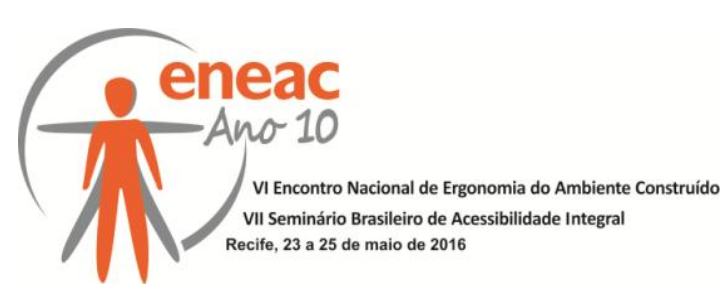

que mais obteve mudanças, o atual tr decaiu 0,61s, devido a grande quantidade de material poroso que isola ainda mais as frequências agudas (Tabela 3).

Tabela 3 - Planilha geral de cálculo de tempo de reverberação corrigido

\begin{tabular}{|c|c|c|c|c|c|c|c|c|c|c|}
\hline \multicolumn{11}{|c|}{ Planilha geral de cálculo de Tempo de Reverberação corrigido } \\
\hline \multirow{3}{*}{ Amb.: } & \multirow{3}{*}{$\begin{array}{l}\text { Auditório do Bloco de } \\
\text { Odontologia das FIP }\end{array}$} & Larg. & Comp. & Alt. & \multicolumn{2}{|c|}{ Volume } & Ocup. & \multicolumn{2}{|c|}{ V/Ocup. } & Tor \\
\hline & & 6,6 & 12,9 & 2,4 & \multicolumn{2}{|c|}{204,336} & 132 & \multicolumn{2}{|c|}{1,55} & 0,72 \\
\hline & & \multicolumn{9}{|c|}{ FREQÜENCIA } \\
\hline \multirow{2}{*}{\multicolumn{2}{|c|}{ Item- Especificação }} & \multirow[b]{2}{*}{ Si } & \multicolumn{2}{|c|}{$500 \mathrm{~Hz}$} & \multicolumn{3}{|c|}{$125 \mathrm{~Hz}$} & \multicolumn{3}{|c|}{$2000 \mathrm{~Hz}$} \\
\hline & & & \multirow{2}{*}{$\frac{\alpha \mathbf{i}}{0,150}$} & Si $x \alpha \mathbf{i}$ & $\alpha i$ & \multicolumn{2}{|c|}{ Si $x \alpha \mathbf{i}$} & $\alpha \mathbf{i}$ & \multicolumn{2}{|c|}{ Si $x \alpha \mathbf{i}$} \\
\hline 1 & $\begin{array}{l}\text { Cadeira estofada com } \\
\text { couro sintético }\end{array}$ & 95,04 & & 14,256 & 0,130 & \multicolumn{2}{|c|}{12,355} & 0,070 & \multicolumn{2}{|c|}{6,653} \\
\hline 2 & $\begin{array}{c}\text { Cortina grossa } \\
\text { drapeada }\end{array}$ & 45,05 & 0,400 & 18,020 & 0,250 & \multicolumn{2}{|c|}{11,263} & 0,600 & \multicolumn{2}{|c|}{27,030} \\
\hline 3 & $\begin{array}{l}\text { Porta de madeira } \\
\text { fechada }\end{array}$ & 1,68 & 0,060 & 0,101 & 0,140 & \multicolumn{2}{|c|}{0,235} & 0,100 & \multicolumn{2}{|c|}{0,168} \\
\hline 4 & Tapete de borracha & 1,24 & 0,080 & 0,099 & 0,040 & 0,0 & 50 & 0,030 & & 037 \\
\hline 5 & $\begin{array}{l}\text { Tábua de madeira } 2,1 \\
\mathrm{~cm}\end{array}$ & 19,28 & 0,100 & 1,928 & 0,100 & 1,9 & 28 & 0,080 & & 791 \\
\hline 6 & $\begin{array}{l}\text { Parede de alvenaria } \\
\text { pintada }\end{array}$ & 49,16 & 0,020 & 1,884 & 0,010 & 0,9 & 42 & 0,020 & & 983 \\
\hline 7 & Carpete de juta & 99,01 & 0,041 & 4,059 & 0,020 & $1,9 \varepsilon$ & 80 & 0,160 & & 842 \\
\hline 8 & Gesso & 98,18 & 0,030 & 2,945 & 0,040 & 3,9 & 27 & 0,020 & & 964 \\
\hline & $\begin{array}{l}\text { Tempo ótimo de } \\
\text { reverberação (s) }\end{array}$ & & 0,72 & & & 06 & & & 72 & \\
\hline Absc & orção total calculada & & 42,39 & & & 23 & & & 22 & \\
\hline & Absorção ideal & & 45,69 & & & 08 & & & 69 & \\
\hline Tem & $\begin{array}{l}\text { ipo de reverberação } \\
\text { calculado (tr) }\end{array}$ & & 0,78 & & & 02 & & & 61 & \\
\hline
\end{tabular}

Fonte: (AUTORES, 2016).

As cortinas grossas quando fechadas, não isolam totalmente o som vindo da parte externa do auditório, porém além de melhorarem o tempo de reverberação contribuem no isolamento acústico, pois formam uma camada superficial extra à parede, ocasionando um pouco de isolamento dos ruídos externos internos do auditório. Essas cortinas devem ter 


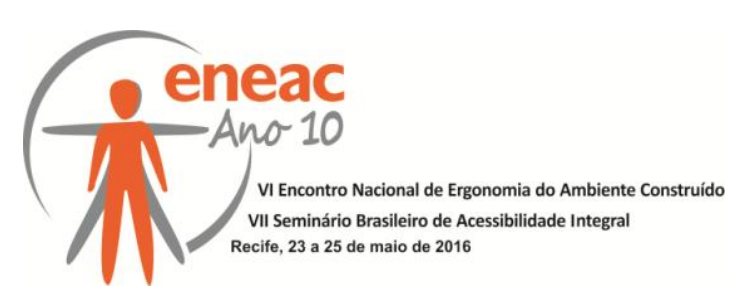

uma espessura de pelo menos $5.08 \mathrm{~cm}$ a $7.62 \mathrm{~cm}$, e terem uma média de peso entre $6.8 \mathrm{~kg}$ a $9.07 \mathrm{~kg}$. O carpete de Juta é um material de baixo custo, de fácil manutenção e composto por fibras biodegradáveis que não prejudicam o meio ambiente, além de não utilizar produtos químicos em sua composição.

Como o objetivo principal dessa mudança é o baixo custo e a sustentabilidade, além de uma reforma que gerasse poucos problemas para ser executada, a incrementação de poucos materiais alcançou o almejado. Além de que os valores para as 03 (três) frequências básicas estudadas estão mais equilibradas, chegando bem próximo ao tempo ótimo de reverberação. O resultado final, com a inserção dos novos materiais, pode ser observado na Figuras 3.

\section{Figuras 3 - Auditório após a inserção dos novos materiais}

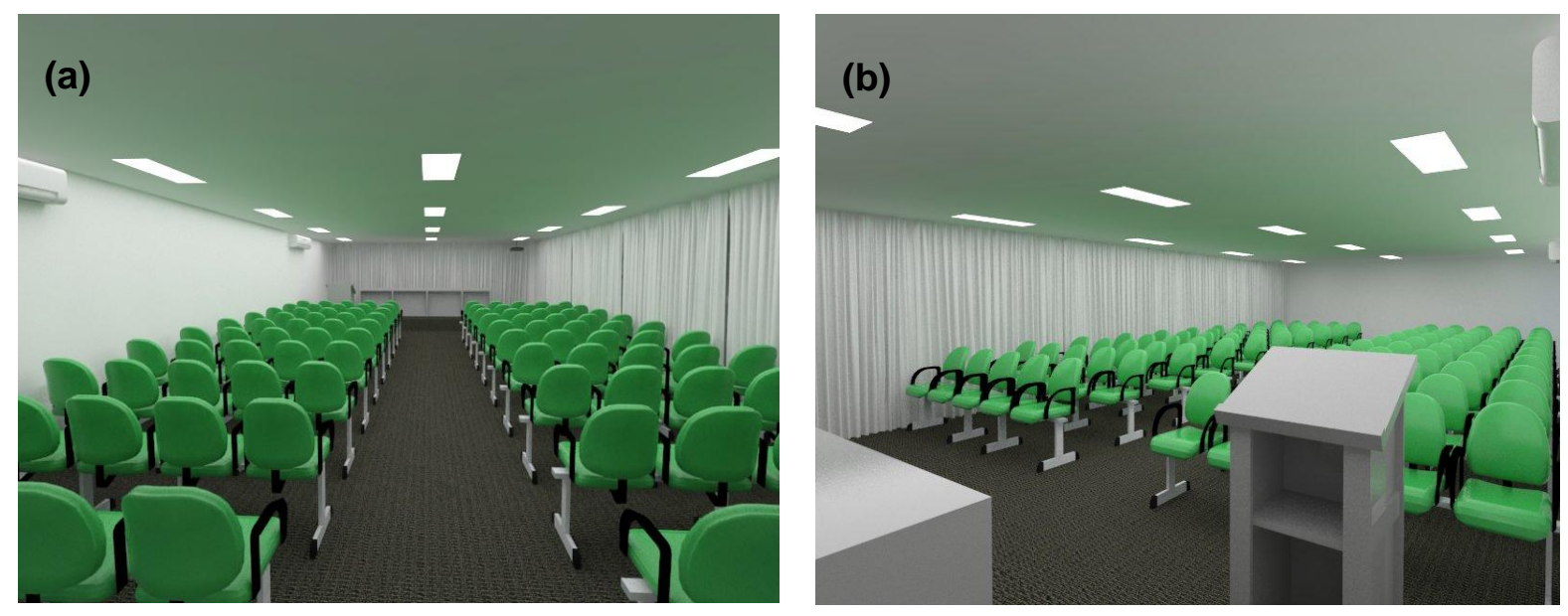

Fonte: (AUTORES, 2016).

\section{CONCLUSÃO}

Apesar da melhor forma de se obter bons resultados, em termos acústicos, é projetar pensando nos materiais do espaço no momento da concepção inicial da edificação, isso não aconteceu no auditório de odontologia das FIP, o que ocasionou a construção de um espaço sem nenhuma adequação as atividades que ali são desenvolvidas. A solução para esse fato foi estudar uma proposta que minimizasse os problemas, sem causar tanta alteração em sua estrutura e em seus materiais existentes.

De acordo com a análise de desempenho acústico, pode-se observar que o tempo de reverberação se encontrou acima dos valores ideais para o auditório nas 03 (três) frequências estudadas, assim como absorção total ideal para elas.

Apesar desta pesquisa ter seu ponto de partida em referências bibliográfias, a respeito de alguns grandes auditórios que possuem boas características acústica, a proposta para a melhoria da qualidade acústica do auditorio de odontologia optou pela vertente da utilização de materiais sustentáveis. Onde, o intuito de melhorar o tempo de reverberação e a absorção sonora, sem o objetivo de reproduzir os modelos estudados anteriormente, foi alcançado. Portando, a pesquisa mostra aos profissionais da área, a importancia da acústica nos ambientes fechados e que de forma simples e prática pode-se obter bons resultados. 


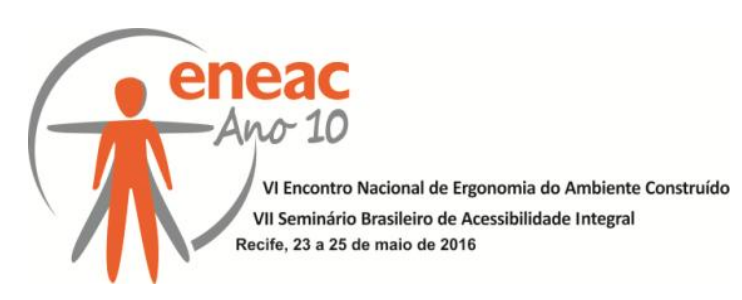

\section{REFERÊNCIAS}

ASSOCIAÇÃO BRASILEIRA DE NORMAS TÉCNICAS. NBR 10152 Níveis de ruídos para conforto acústico. Rio de Janeiro, 1987.

ASSOCIAÇÃO BRASILEIRA DE NORMAS TÉCNICAS. NBR 12179 Tratamento acústico de recintos fechados. Rio de Janeiro, 1992.

DE MARCO, Conrado Silva. Elementos de acústica arquitetônica. São Paulo: Nobel, 1982.

MAIA, M.L.; SALGADO, M.S. Qualidade do projeto e desempenho do edificio: uma discussão sobre o proceso do projeto. In: $\vee$ Workshop Brasileiro de Gestão de Processo do Projeto na Construção de Edifícios, 5, 2005, Florianópolis. Anais...Florianópolis, SC, UFSC, 2005.

SILVA, P. Acústica arquitetônica e condicionamento de ar. 5. Ed. Belo Horizonte. EDTAL E.T. Ltda, 2005.

SIMÕES, F.M. et al. Acústica arquitetônica. Procel Edifica - Eficiência Energética em Edificações, 2011. 123 p.

SOUZA, L. C. L., AIMEIDA, M. G.; BRAGANÇA L. de. Bê-á-bá da acústica arquituitetônica. São Carlos: EDUFSCAR, 2006. 